\title{
LIVING CONDITIONS AND HEALTH
}

\begin{abstract}
A
MEDICAL conference on "The Influence of Living and Working Conditions upon Health" was held at Cannes during September 27-29, under the chairmanship of Prof. J. Parisot, former president of the World Health Assembly, and Prof. J. de Castro, formerly president of the United Nations Food and Agriculture Organization. The French Ministry of Health and Atomic Energy Commission were represented.

In the section on nutrition the diverse ways in which food factors operate were discussed on a world level by de Castro, while Cicely Williams laid stress on the social factors that might often exceed the physiological in a given food situation. According to Yang-En-Fu, recent examination of the high cereal diet common in China had shown evidence of reasonable adequacy of its vegetable protein with consequently less necessity for substitution by meat; local vegetable foods, fortified by vitamins and minerals, could be expected to correct the main deficiencies of this diet.

D'Arcy Hart considered that the highly efficient chemotherapy now available against tuberculosis imposes some re-thinking on nutritional policy in relation to this disease in under-developed countries. It is imperative to discover whether such chemotherapy is effective in the malnourished, so that mass chemotherapy can be integrated with general social and nutritional improvements; probably host resistance to infection remains important for healing, however potent the drugs may be in the initial stages of treatment. Techniques and factors, particularly
\end{abstract}

psychological, in the study of fatigue in industry were discussed by Desoille and Le Guillant in the section on work factors, while problems of industrial disease in various occupations were presented by other speakers. These include Reysek, who told of some apparently new types of pulmonary exercises being tried in Czechoslovakia for silicotics, which were suggested by observations on glass blowers.

The third main topic on late effects of ionic radiations was introduced by Lacassagne, who concluded that collective moasures, which would restrict the almost inevitable increase in the chance of the total population being exposed to a supplementary dose of such radiations, should not be delayed. The results of a follow-up in 1956 on the changes in blood and bone marrow in survivors of Hiroshima were given by Kono, who said that, apart from leukæmia, significant abnormalities were found on close examination of some apparently normal persons. Peacock pointed out the possible future carcinogenic dangers from radioactive isotopes. The general view of the speakers seemed to be that practice had outrun experiment and safety tests.

The conference concluded by forming an "International Medical Association for the Study of Health and Living Conditions"*, which, it is assumed, will sponsor the recently published journal Living Conditions and Health, the first two numbers of which have appeared in no less than six languages.

- Secretariat : Helferstorferstrasse 4/12/III, Vienna 1.

\section{IMMUNITY IN PARASITISM}

"T HE Nature of Immune Responses in Parasitism" was the subject discussed at a meeting of the Parasitology Group, Institute of Biology, on October 18, at 41 Queen's Gate, London, S.W.7. Three speakers were invited to read pepers.

Dr. M. Robertson (Lister Institute) summarized the results of the invostigation into the antibody response of cows and heifers to infection with Trichomonas foetus. This work was carried out in collaboration with Dr. W. R. Kerr, of the Ministry of Agriculture, Northern Ireland.

The parasite develops in the uterus, and antigen, probably from the breakdown of the trichomonads, passes into the lymph glands and blood stream, resulting in the production of circulating agglutinins. The antibody in the blood stream has no protective value as it does not come into contact with the trichomonads at the site of infection.

The presence of $T$. foetus in the uterus stimulates the local production of antibody, which in acute cases of the disease appears to have a briof protective value in early re-exposure to infection.

Antigen passes out from the uterus, and antibody is produced in the circulating blood; but antibody does not pass back from the blood into the uterus. Trichomonads from the uterus appear in the vagina, sometimes in great numbers. Their presence stimulates the appearance of antibody in the vaginal mucin which causes the temporary disappearance of the trichomonads from the vagina, but does not have any value in protecting the animal from re-infection.

The vaginal antibody is probably produced locally. It is of great diagnostic value.

The antibody reactions of the rat to infection with Trypanosoma lewisi were briefly described. The trypanocidal antibody and the growth-and divisioncontrolling antibody, or ablastin, studied by Taliaferro were referred to, and further work on the nature of ablastin was mentioned.

Dr. E. J. L. Soulsby (Cambridge) presented work concerned with immunological responses of the host to helminth infestations.

The way in which immune mechanisms may modify naturally ocurring helminth infestations was briefly indicated, with particular references to gastrointestinal nematodes of sheep. It wes shown that the degree of immunity of the host, as measured by antibody-levels, was inversely proportional to the intensity of infestation and to the level of egg production. An almost complete elimination of previously high infestations occurred in early summer, and this was associated with a marked immunological response by the host. Following the elimination of the helminths, a period of protection was estab. lished in the sheep despite persistent reinfestation. 
More detailed work with Ascaris lumbricoides in the guinea pig showed that a marked immunity to re-infestation can be induced by administering infective stages orally or by alternative routes. With the exception of the 'metabolic products' of thirdstage larvæ, non-viable worm material induced no protective immunity in the guinea pig. The critical period for the release of helminth antigen, which ultimately induces protective immunity, appears to be from four to six days after infestation. The earlier larval stages appear to be unimportant in stimulating immunity. During the period of four to six days after infection the second-stage larvæ moult, but in an immune host the growth of the larvæ is inhibited and they do not reach the size at which moulting normally occurs. Using a natural marker antibody (Forssman antibody), it was found that the poriod between the fourth and fifth days after infection was the earliest time at which a marked release of antigen could be expected. Since this period coincides with the commencement of moulting, the moulting process is strongly suspected as an important mechanism for the release of antigens which stimulate protective immunity in the host.

Dr. K. Mellanby (Rothamsted Experimental Station) spoke at short notice, in place of Prof. R. M. Gordon, on reactions to insect bites and infestation by mites and ticks.

Individual animals respond differently to the bites of particular insects, and the responses change with the period and intensity of the attack. Two and possibly three antigens may be involved. The first evokes a weal 5-10 min. after exposure. The second antigen produces the delayed, tuberculin-type reaction some hours after exposure. Thirdly, there may be a more serious, generalized reaction, distinct from the delayed reaction and possibly related to a third antigen. The antigens are injected with the saliva of the biting insects, but also occur in their tissues. Thus, extracts of larval, pupal and male mosquitoes may give similar reactions to the bites of adult females. Reactions to non-biting insects (for example, sensitization to locusts) are essentially similar to reactions to bites.

A previously unexposed person may not react to a first bite. However, after exposure he shows the immediate reaction to a bite, and on further exposure shows the delayed reaction as well. Generally, further exposure causes the delayed reaction to disappear, and prolonged exposure may eliminate the immediate reaction also.

The reaction of the host does not affect the feeding of most blood-sucking insects, but the feeding of mites and ticks, which may take some days to engorge, may be interrupted in sensitized hosts by the infiltration of leucocytes around the mouth. parts. Sensitization to the scabies mite Sarcoptes causes local cedema and the mites tend to leave their burrows; the sensitized individual may be virtually immune to scabies.

Other workers have reported differences in the reaction to bites of clean insects and those infected with parasitic diseases. In the rickettsial disease, scrub typhus, infecting bites may give characteristic local lesions not caused by uninfected mites.

June Mahon

\section{INTERNATIONAL SCIENTIFIC RADIO UNION}

T HE twelfth general assembly of the International Scientific Radio Union was held at Boulder, Colorado, during August 22-September 5 and was attended by more than 550 delegates and observers from twenty-seven countries. The meetings of the full assembly and of the executive and organization committees were held under the chairmanship of Father P. Lejoy, who was serving a second term as president of the Union. This was the first assembly since the recently constituted national committees in Austria, Greece and the U.S.S.R. had been formed; delegates from these countries were warmly welcomed, and they took an active part in the scientific work of all the meetings in Boulder.

As is probably now well known, the main functions of the Union are to promote and organize radio research requiring international co-operation and to encourage the setting-up of such common methods of measurement as may be required for the study of any radio phenomena, whether or not these be directly associated with the Earth and its atmosphere. The work is carried out by seven commissions, each of which is concerned with specific aspects of radio research, and ranging from measurements and standards, and the use of circuits and electronics techniques to all aspects of wave propagation, and terrestrial or atmospheric noise and the important new developments in radio astronomy.

Detailed accounts of the work of each commission will be published in due course in the "Proceedings of the General Assembly". In the meantime, the results of this work are crystallized in the resolutions which each commission made and presented to the assembly for adoption. These resolutions are being printed in the Information Bulletin of the Union, which is published by the Secretary-General at 7, place Emile Danco, Uccle-Brussels (Belgium). The most recently issued Bulletin-No. 105-contains the recommendations and resolutions of Commissions $1,2,5$ and 6 , and those of the remainder will presumably be in a later issue. A list of the commissions, with their officers and the national official members, is also given in the same Bulletin.

Prior to the general assembly in Boulder, meetings were held in New York of the Mixed Commission on the Ionosphere under the chairmanship of Sir Edward Appleton, and of the Joint Commission on Radiometeorology with Dr. W. E. Gordon as chairman. The work of these groups is conducted in close co-operation with the corresponding commissions of the International Scientific Radio Union, namely 3, "Ionospheric Radio" and "Radio and Troposphere", of which Drs. D. F. Martyn and R. L. Smith-Rose, respectively, were re-elected chairmen.

At the closing meeting, Dr. L. V. Berkner was elected president, and it was decided that the next general assembly would be held in the United Kingdom in 1960. A revised scale of national subscriptions was introduced, and provision was made for the organization between general assemblies of international symposia on specialized subjects relating to radio scientific matters. 